\title{
Abordagem crítico-interpretativa das fragilidades e potencialidades do trabalho de enfermagem aos ianomâmis, Amazonas
}

Este estudo analisa as fragilidades e potencialidades do processo de trabalho de enfermagem desenvolvido nas comunidades indígenas ianomâmis, dos municípios de Barcelos e Santa Isabel do Rio Negro, estado do Amazonas. Trata-se de uma pesquisa qualitativa, de abordagem crítico-interpretativa, realizada em 2006. Informantes-chave: três enfermeiros e 17 técnicos de enfermagem. As informações foram obtidas por meio de entrevistas. Para a interpretação, optou-se pelo método da análise de conteúdo, com emprego da técnica analítica de enunciação com transversalidade temática constituinte de duas categorias - fragilidades e potencialidades. As fragilidades desvelam o gerenciamento do serviço de enfermagem em área indígena e a escassez de recursos humanos e de materiais. As potencialidades revelam o trabalho em equipe e a presença dos agentes indígenas de saúde nas aldeias. Conclui-se que a situação dos trabalhadores de enfermagem descrita nos discursos dos entrevistados requer atenção dos gestores da saúde indígena, para dar condições mais dignas de trabalho.

Descritores: Enfermagem, Saúde Indígena, Cuidados de Enfermagem, Serviço de Enfermagem.

\section{Critical-interpretative approach of fragilities and potentialities of the nursing work for yanomamis, Amazon}

This study analyzes the fragilities and the potentialities of nursing working process developed in autochthonous yanomamis communities, at municipal districts of Barcelos and Santa Isabel do Rio Negro, Amazon state. That is a qualitative investigation with a critical-interpretive approaching, accomplished in 2006. Main informers: three nurses and seventeen nursing assistants. The informations were obtained by means of interviews. To the interpretation, it was opted for the method of the analysis of the content, by using the enunciation analytical technique with thematic transverse, constituting two categories that are fragilities and potentialities. The fragilities discoveries show: the management of the nursing service in autochthonous area, the shortage of human resources and of materials. The potentialities reveal the team work and the presence of indigenous Agents of health in the villages. It is concluded that the situation of the nursing workers described in the speeches of the interviewed requires attention of the indigenous health managers, giving them better conditions of work.

Descriptors: Nursing, Indigenous Health, Nursing Care, Nursing Service.

\section{Enfoque crítico-interpretativo de las debilidades y potencialidades del trabajo de la enfermería para yanomamis, Amazonas}

El estudio analiza las debilidades y las potencialidades del proceso del trabajo que la enfermería desarrolló en las comunidades autóctonas yanomamis, de los distritos municipales de Barcelos y Santa Isabel do Rio Negro, Amazonas. Se trata de una investigación cualitativa, de enfoque crítico-interpretativo con desenrollo en el año de 2006. Informante-clave: tres enfermeras y diecisiete técnicos de enfermería. Las informaciones fueron obtenidas por entrevista. Para la interpretación se optó por el método del análisis del contenido, con el trabajo de la técnica analítica de la enunciación con componente transversal temático de dos debilidades de categorías y potencialidades. Las debilidades muestran: el gerenciamiento del servício de enfermería en la área indígena, la escasez de recursos humanos y de materiales. Las potencialidades revelan el trabajo en equipo, la presencia de los agentes indígenas de salud en las comunidades. Se concluye que la situación descrita de los trabajadores de enfermería en los discursos de los entrevistados requiere atención de los administradores de la salud indígena ofreciendoles condiciones más dignas de trabajo.

Descriptores: Enfermería, Salud Indígena, Atencíon de Enfermería, Servícios de Enfermería.

\section{INTRODUÇÃO}

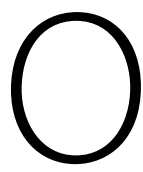

Subsistema de Atenção à Saúde Indígena (Sasi) foi instituído pela lei no 9836 , de 23 de setembro de 1999, no âmbito do Sistema Único de Saúde (SUS). Com isso, no intuito de descentralizar os serviços de saúde, o Ministério da Saúde (MS) criou os Distritos Sanitários Especiais Indígenas (Dsei) como elementos da primeira esfera de atenção integrada ao índio no âmbito SUS, ou seja, na atenção básica à saúde. No Brasil, existem
$34 \mathrm{Dsei}^{(1)}$, dos quais sete estão localizados no estado do Amazonas, lócus de trabalho direto de profissionais de saúde aos povos indígenas da Amazônia.

O trabalho na assistência aos indígenas requer do profissional de saúde a apreensão de conhecimentos transdisciplinares à prática no campo da saúde coletiva, numa implicação axiomática de disciplinas conexas das áreas das ciências da saúde, humanas e sociais ${ }^{(2)}$, ligadas a um

1 Enfermeiro. Mestre em saúde, sociedade e endemias - Ufam/Ufpa/Fiocruz.

2 Enfermeiro. Doutor em enfermagem - UFC. Professor da Escola de Enfermagem de Manaus - Universidade Federal do Amazonas. E-mail: davidnetto@ufam.edu.br. 
novo campo disciplinar de compreensão da complexidade do processo saúde-doença-cuidado indígena - processo instrumental teórico-prático de ancoragem das práticas e da organização dos serviços ${ }^{(3)}$.

Nessa perspectiva transdisciplinar, o processo de trabalho de enfermagem na atenção à saúde indígena tem se diversificado, carreado para as novas realidades do cuidar, especificamente ao indivíduo índio, a grupos étnicos e às comunidades indígenas por meio de ações educativas e gerenciais, como prática sociointerativa na saúde, na educação e na gestão dos serviços de saúde e de enfermagem ${ }^{(4)}$, numa comunicação proxêmica dos sujeitos construtores do cotidiano do cuidar.

Assim, o trabalho do enfermeiro é uma correlação entre práticas e necessidades de saúde ${ }^{(5)}$. Esse processo tem múltiplos fatores condicionantes do estado de saúde ou de doença de indivíduos ou grupos, sejam eles sociais, econômicos, políticos, ideológicos ou culturais, além da capacidade exercida pelas práticas de modificar uma dada situação de saúde, atendendo ou não às necessidades de saúde de determinada população.

$\mathrm{O}$ estudo tem por objetivo analisar as fragilidades e potencialidades do processo de trabalho de enfermagem desenvolvido nas comunidades indígenas ianomâmis, dos municípios de Barcelos e Santa Isabel do Rio Negro, estado do Amazonas, Região Norte do Brasil.

\section{Metodologia}

Pesquisa qualitativa, exploratório-descritiva, de abordagem crítico-interpretativa, realizada na área indígena ianomâmi, nos municípios de Barcelos e Santa Isabel do Rio Negro, estado do Amazonas, Região Norte do Brasil, em 2006.

Os sujeitos informantes-chave da pesquisa foram três enfermeiros e 17 técnicos de enfermagem. A coleta das informações foi realizada por meio da técnica de entrevista, com interpretação pelo método da análise de conteúdo ${ }^{(6)}$. O exame das informações foi sequenciado em três polos cronológicos: pré-análise: leitura flutuante do material constituinte do corpus; exploração do material: codificação e recortes dos elementos constitutivos do objeto de estudo em duas categorias - fragilidades e potencialidades; tratamento e interpretação: processo analítico de significação e validação dos resultados.

O projeto recebeu parecer de aprovação pelo Comitê de Ética em Pesquisa da Universidade Federal do Amazonas, sob o número $231 / 2006$.

\section{Resultados}

\section{Fragilidades}

A fragilidade da vida humana(7) envolve o ser numa compreensão holística e fenomenológica como sujeito exposto às fraquezas naturais do social, do corpo, da mente e do espírito. Esses pontos frágeis podem acometer o ser inclusive no exercício laboral. No contexto do trabalho, as fragilidades apontadas pelos enfermeiros e técnicos de enfermagem tiveram como subcategorias a estrutura, o acesso, a cultura e o gerenciamento.

O marco conceitual donabediano ${ }^{(8)}$ de estrutura, referindose a esse termo para a descrição do modelo organizacional dos estabelecimentos de saúde, serve, também, para descrever a estrutura organizacional do Distrito Sanitário Especial Indígena Yanomami (Dsei-Y). Quanto à análise da estrutura, os depoimentos revelam que uma boa infraestrutura favorece $o$ atendimento aos indígenas, e, por conseguinte, a resultados satisfatórios no fim da assistência - a cura. A estrutura está vinculada aos recursos físicos e materiais e ao atendimento prestado: "Você às vezes perde muito mais tempo tentando consertar o posto de saúde do que fazendo seu atendimento. Então, a estrutura prejudica muito, tanto pelo material em más condições de uso quanto, às vezes, pela falta dele".

O acesso, enunciado como logística de transporte, foi considerado uma fragilidade que prejudica a assistência. "O que acho muito difícil e que atrapalha nosso trabalho em área é o transporte. Houve um acidente em que o paciente teve a cabeça quebrada (...) não tínhamos como transferi-lo porque não havia nenhum bote, e a gente ficou uns dois dias para conseguir remover o paciente grave."

Outra fragilidade relativa ao acesso são as barreiras geográficas tanto no trajeto de ida quanto no retorno às aldeias, sendo fatores de risco acidentes de trabalho e doenças ocupacionais. "As viagens sempre acontecem com o bote muito cheio. É um risco grande. Toda vez que você viaja, sabe que está entrando, mas não sabe se vai chegar ao destino." "Os rios são cheios de corredeiras, a correnteza é forte e os leitos são repletos de pedras, dificultando o acesso."

As fragilidades na execução das ações em área indígena evidenciam-se, sobretudo, por meio dos aspectos emocionais relacionados à longa escala de trabalho em área, que compreende um período de 30 a 60 dias. O fato de os enfermeiros e técnicos de enfermagem permanecerem nas aldeias, longe dos laços familiares e de amizades, leva-os à solidão, ao medo e até mesmo ao estresse. Assim sendo, "solidão, tristeza, saudades da família são dificuldades que a gente passa ao trabalhar em área".

Percebe-se que, ao esvaziar-se dos laços afetivos urbanos, tanto enfermeiros quanto técnicos de enfermagem mergulham num conflito interior decorrente do medo do desconhecido e do receio dos novos sujeitos com quem vão conviver - os indígenas. "Quando entramos em área, nosso semblante muda, não sabemos o que pode acontecer, pois eles (índios) não nos conhecem e nós não os conhecemos."

Quanto à cultura, ela deve ser lida no cotidiano do mundo do trabalho de maneira polissêmica, significando características e atos comportamentais humanos enraizados nas relações sociais capazes de gerar signos e significados ${ }^{(9)}$. A cultura indígena, com singularidades advindas das etnias e seus respectivos padrões culturais, constituiu, para os enfermeiros e técnicos 
de enfermagem, uma fragilidade atrelada ao gerenciamento por dificultar tanto o planejamento e a programação quanto a execução das ações de enfermagem.

O padrão cultural diferenciado faz com que as relações sociais dos ianomâmis sejam sui generis em nível de comunidade e interpessoal, pelo modo como o indivíduo não-índio olha a realidade, que passa a ser composta pelo universo macroscópico de significados estabelecidos pela lente da sociedade atrelada à subjetividade. Dessa forma, observa-se que os padrões culturais que as pessoas utilizam para interpretar um dado episódio de doença são criações sociais formuladas a partir de processos de definição e interpretação constituídas intersubjetivamente e distanciadas da compreensão antropológica do ser índio sobre o homem e o ambiente.

Essas criações sociais norteiam as relações comunitárias estabelecidas na sociedade ianomâmi. Elas constituem-se, para os enfermeiros e técnicos de enfermagem, em fragilidade tanto para a execução das ações relacionadas ao processo saúde-enfermidade-cuidado quanto para o estabelecimento do convívio. "Outra questão é em relação à aceitação dos profissionais sobre a cultura deles e vice-versa. Quando entramos em área, somos esclarecidos de que não devemos interferir na cultura dos índios, então é muito difícil, pois, temos um impacto cultural muito grande quando chegamos em área."

Todavia, na tentativa de minimizar o problema da barreira cultural no Alto Rio Negro, o Instituto Sócio-Ambiental (ISA), com o apoio do Ministério da Educação, por meio da educação indígena, tem buscado estabelecer uma política de educação escolar indígena, visando à implementação de uma educação diferenciada que corresponda aos anseios das comunidades indígenas, com garantia das questões relativas à saúde em cartilhas e folhetos ${ }^{(10)}$, ação essa de inclusão dos profissionais de saúde nesse itinerário educativo emancipador.

O gerenciamento de enfermagem foi verbalizado em diversos discursos dos entrevistados como uma fragilidade que influencia negativamente nas ações de saúde. "A falta de supervisão é um ponto negativo. O enfermeiro como gerente esteve ausente. Acho que faltou a liderança dos enfermeiros para conduzir o trabalho em área. Muitas reclamações vieram até mim pela ausência do profissional enfermeiro. E, quando digo ausência, eu me refiro à ausência de intervenção desse profissional."

Enfáticos sobre a ingerência do enfermeiro em área, os técnicos de enfermagem afirmam que a ausência desse profissional é motivo de estresse por conta da complexidade de algumas intervenções que Ihes são peculiares. "A presença do enfermeiro é muito importante porque alguns casos devem ser repassados para ele resolver, e às vezes a gente não tem como. Porque, se fizermos um procedimento errado, aí vai cair em cima do técnico." Interpreta-se esse enunciado como preocupação dos técnicos de enfermagem com o exercício legal da profissão, cabendo aos enfermeiros, como gestores e líderes natos da enfermagem, fazer cumprir o que estabelece a legislação(11).

\section{Potencialidades}

As potencialidades, a nosso ver, são um conjunto de possibilidades que aguardam realizações, ou seja, o vir a ser. No ambiente do trabalho, as potencialidades decorrem da interface com o ambiente interno e com as pessoas, as quais proporcionam o potencial interativo simbólico humano.

O comprometimento e a interação desses profissionais com a comunidade foram considerados potencializadores das ações de saúde. Destaca-se o comprometimento dos técnicos de enfermagem, que permanecem constantemente e por um longo período nas aldeias, e dos Agentes Indígenas de Saúde (AIS), que constituem uma força de trabalho importante para aproximar os sistemas de saúde tradicional e ocidental. "O técnico é o principal instrumento de trabalho que existe na área. Não se pode comparar com nenhum outro técnico de cidade, porque ali a gente faz tudo. A gente é psicólogo, médico, tudo dentro da área." "Os AIS são o principal intercâmbio entre o enfermeiro e técnicos de enfermagem e a comunidade."

Por esse prisma, vale ressaltar que o trabalho em área indígena é diferenciado por diversos aspectos, como o deslocamento do profissional para a aldeia, com sua imersão num mundo imaginário, muitas vezes desconhecido, além do vínculo profissionalindígena, que deve ser estabelecido pela criação de elos e laços sociais, o que requer capacitação antropológica.

Outra potencialidade destacada foi a educação em saúde, sendo considerada

pelos profissionais deenfermagem como práxis transformadora das condições sociais e de melhoria da qualidade de saúde da população indígena, numa perspectiva de promoção da saúde, prevenção de enfermidades e educação permanente. Nota-se a importância dada à educação em saúde e à educação permanente, ambas como ato educativo e de vínculo de cuidado no trabalho da enfermagem. "As palestras também são um ponto forte, as reuniões educativas são muito importantes para eles entenderem qual é nossa finalidade lá dentro, que não é só curar as doenças, é fazer com que eles não adoeçam." "Eu acho que tudo que vier como capacitação para o profissional que trabalha em área indígena é bem-vindo, porque, mais cedo ou mais tarde, você vai precisar desse conhecimento. Porque ele vai depender dessa instrução para, mais à frente, fazer um trabalho de qualidade."

Bens públicos que fundamentam a promoção da vida, a educação e a saúde mereceram do Ministério da Saúde especial atenção em 2004. Foi quando se institucionalizou a Política Nacional de Educação Permanente em Saúde como estratégia do Sistema Único de Saúde para a formação e o desenvolvimento de trabalhadores, com processos de capacitação a partir da metodologia problematizadora freireana, com o pressuposto de que a construção do saber técnico-científico emane da 
realidade vivenciada para ser objeto de transformação das práticas na rede de serviços ${ }^{(12)}$.

Nesse contexto interdisciplinar, L'Abbate ${ }^{(13)}$ divide a demanda dos profissionais na área da educação em saúde em duas vertentes: a primeira, direcionada para instrumentalização em técnicas didático-pedagógicas, de aprendizagem de realização do trabalho em grupo; a segunda, o desenvolvimento do papel do profissional, tem como conceito base o campo profissional, dimensionado nas competências e habilidades de cada profissional de saúde. Considera que qualquer tipo de atuação que vise a melhorar o serviço de saúde deve passar por capacitação dos profissionais de saúde, de modo a buscar o aperfeiçoamento das relações sociais das práxis dos serviços por sujeitos/cidadãos do processo.

\section{Considerações finais}

Fragilidades e potencialidades permearam os discursos dos informantes do estudo. A estrutura e o acesso representam pontos frágeis na execução dos serviços de saúde na opinião dos técnicos entrevistados.

A interação entre equipe de saúde e comunidade foi considerada um ponto forte para o desenvolvimento das atividades de enfermagem. A atuação dos Agentes Comunitários Indígenas de Saúde foi referida como importante para a resolução das atividades de saúde nas aldeias.

Na concepção dos enfermeiros e dos técnicos de enfermagem, o acesso à área indígena e o gerenciamento em enfermagem nas aldeias são colocados como principais barreiras que fragilizam o trabalho em área indígena, seguidos dos aspectos culturais das diferentes etnias, que interferem diretamente nas atividades de saúde e de enfermagem.

Concernente às potencialidades, enfermeiros e técnicos de enfermagem consideram os AIS como uma força de trabalho que corrobora para o desenvolvimento das atividades de saúde nas aldeias. A educação em saúde e a interação da equipe de enfermagem com as comunidades indígenas são apontadas como fortalezas capazes de influenciar nas ações de saúde em área indígena.

Por fim, acredita-se que a situação dos trabalhadores de enfermagem na atenção à saúde indígena requeira mais atenção, no sentido de dar a eles condições dignas de trabalho.

\section{Referências}

1. Brasil. Fundação Nacional de Saúde. Política nacional de atenção à saúde

dos povos indígenas. $2^{\mathrm{a}}$ ed. Brasília: Ministério da Saúde, FNS; 2002.

2. Raynaut C. Interfaces entre a antropologia e a saúde: em busca de novas

abordagens conceituais. Rev Gaúcha Enferm. 2006;27(2):149-65.

3. Rocha SMM, Almeida MSP. O processo de trabalho da enfermagem

em saúde coletiva e a interdisciplinaridade. Rev Latinoam Enferm.

2000;8(6):96-101.

4. Kurcgant P. Gerenciamento em enfermagem. Rio de Janeiro: Guanabara

Koogan; 2005.

5. Silva LMV, Formigli VLA. Avaliação em saúde: limites e perspectivas. Cad

Saúde Pública. 1994;10(1):80-91.

6. Bardin L. Análise de conteúdo. Lisboa: Ediçōes 70; 2004.

7. Herzlich C. Fragilidade da vida e desenvolvimento das ciências sociais no

campo da saúde. Physis. 2005;15(2):193-203.
8. Melleiros MM, Gualda DMR. A abordagem fotoetnográfica na avaliação de serviços de saúde e de enfermagem. Texto \& Contexto Enferm. 2006;15(1):82-8.

9. Geertz C. A interpretação das culturas. Rio de Janeiro: Zahar; 1978.

10. Instituto Sócio Ambiental. Políticas de educação escolar indígena no Rio Negro avançam [Internet]. [citado em 2007 Ago 15]. Disponível em: www. socioambiental.org/nsa/detalhe?id=2269.

11. Conselho Federal de Enfermagem. Lei № 7.498 [Internet]. [citado em 2007 Ago 15]. Disponível em: http://www.portalcofen.gov.br/2007/materias. asp?ArticlelD=22\&sectionID=3.

12. Almeida $L P G$, Ferraz CA. Políticas de formação de recursos humanos em saúde e enfermagem. Rev Bras Enferm. 2008;61(1):31-5.

13. L'abbate S. Educação em saúde: uma nova abordagem. Cad Saúde Pública. 1994;10(4):481-90. 